\title{
MicroRNA-30d-5p promotes ovarian granulosa cell apoptosis by targeting Smad2
}

\author{
MIAOMIAO YU and JINXIA LIU
}

\begin{abstract}
Department of Obstetrics and Gynecology, Eastern Theater General Hospital, Nanjing, Jiangsu 210002, P.R. China
\end{abstract}
Received February 1, 2019; Accepted August 30, 2019

DOI: $10.3892 /$ etm.2019.8184

\begin{abstract}
Polycystic ovarian syndrome (PCOS) is one of the leading causes of female infertility. MicroRNA-30d-5p (miR-30d-5p) has been reported to be significantly increased during follicle stimulating hormone (FSH)-mediated progesterone secretion of cultured granulosa cells. However, its role in the proliferation and apoptosis of ovarian granulosa cells is unclear. The present study aimed to investigate the role of miR-30d-5p in the proliferation and apoptosis of ovarian granulosa cells. Bioinformatic analysis and dual-luciferase reporter assay were used to predict and confirm the direct target of miR-30d-5p. The levels of miR-30d-5p were detected via reverse transcription-quantitative PCR (RT-qPCR), cell proliferation was detected via an MTT assay and cell apoptosis was measured via flow cytometry. The levels of phosphorylated (p)-Smad2, Smad2, p-Smad3 and Smad3 were detected by performing a western blot assay or RT-qPCR. In the present results, Smad2 was identified as the direct and functional target of miR-30d-5p. Compared with the control and control plasmid groups, the Smad2 plasmid significantly enhanced Smad2 mRNA levels in rat ovarian granulosa cells, enhanced rat ovarian granulosa cell viability and reduced cell apoptosis. In addition, the results demonstrated that overexpression of miR-30d-5p significantly decreased the level of Smad2, the effect of which was reversed by the Smad2-plasmid. Furthermore, it was demonstrated that the enhanced expression of miR-30d-5p significantly inhibited ovarian granulosa cell proliferation and promoted cell apoptosis. Restoration of Smad 2 reversed the effect of miR-30d-5p on ovarian granulosa cell proliferation and apoptosis. Transfection with miR-30d-5p mimics significantly decreased the expression of Smad2 and increased the relative $\mathrm{p}-\mathrm{Smad} 2 / \mathrm{Smad} 2$ and $\mathrm{p}-\mathrm{Smad} 3 / \mathrm{Smad} 3$ levels in ovarian granulosa cells, which was reversed by overexpressing Smad2. The present study demonstrated that
\end{abstract}

Correspondence to: Ms. Jinxia Liu, Department of Obstetrics and Gynecology, Eastern Theater General Hospital, 305 Zhongshan East Road, Xuanwu, Nanjing, Jiangsu 210002, P.R. China

E-mail: liujx171718@163.com

Key words: polycystic ovary syndrome, microRNA-30d, Smad family member 2 , apoptosis the overexpression of $\mathrm{miR}-30 \mathrm{~d}-5 \mathrm{p}$ reduced proliferation and induced the apoptosis of granulosa cells by targeting Smad2. The molecular mechanism of ovarian granulosa cell apoptosis may therefore be explained by the newly identified miR-30d-5p/Smad 2 axis, which represents a novel potential treatment target for PCOS.

\section{Introduction}

Polycystic ovary syndrome (PCOS) is the most common endocrine disorder in women of reproductive age and is the leading cause of female infertility (1). Although the clinical and biochemical characteristics of PCOS are heterogeneous, abnormal folliculogenesis is still considered an important clinical feature of PCOS (2). During follicular development, a large number of follicles undergo atresia, a process tightly controlled by the fine balance between survival and apoptotic factors $(3,4)$. The process is also regulated by endocrine, autocrine and paracrine factors (5). Normal follicle development depends on the balance between proliferation and apoptosis. Alterations in the ovarian microenvironment that present follicular cysts could alter the normal processes of ovarian cell proliferation and programmed cell death leading to a variety of fertility problems including PCOS $(6,7)$. It has been speculated that abnormal folliculogenesis and degeneration of the granulosa cell layers is caused by the abnormal proliferation and/or apoptosis of follicular granulosa cells, resulting in failure in further development $(8,9)$. However, the mechanism underlying abnormal folliculogenesis is not fully understood.

MicroRNAs (miRNAs) are highly conserved, $18-25$ nucleotide non-coding RNA molecules that post-transcriptionally regulate mRNA expression by binding to their 3'untranslated regions (UTRs) (10). miRNAs have been implicated in various biological and cellular processes including cell proliferation, differentiation and apoptosis $(11,12)$. Evidence has demonstrated that certain miRNAs are involved in the regulation of ovarian granulosa cell proliferation and apoptosis $(13,14)$. miR-30d-5p has been studied in several cancers including cervical cancer, non-small cell lung cancer, prostate cancer, gallbladder carcinoma and human colon cancer (15-19). miR-30d-5p has also been reported to serve critical roles in acute ischemic stroke-induced, autophagy-mediated brain injury (20). A previous study reported that miR-30d-5p is significantly increased during follicle stimulating hormone 
(FSH)-mediated progesterone secretion of cultured granulosa cells (21). However, the effect of miR-30d-5p on ovarian granulosa cell apoptosis and its potential mechanism has not been fully elucidated.

The transforming growth factor- $\beta$ signaling pathway participates in various cellular processes, including cell growth, differentiation, apoptosis and homeostasis, and is mediated by a complex of membrane-bound type I and type II receptors with Smad proteins functioning as intracellular mediators $(22,23)$. Smad2 belongs to the receptor-activated Smad family and it serves a key role in regulating cell proliferation and apoptosis (24). Abnormal proliferation and/or apoptosis in granulosa cells have an important role in PCOS $(8,9)$. Therefore, Smad 2 may be crucial to PCOS. To the best of our knowledge, the role of Smad2 in POCS remains largely unclear with the relationship between miR-30d-5p and Smad2 being unknown.

The present study investigated the role of miR-30d-5p in ovarian granulosa cell proliferation and apoptosis to elucidate the underlying molecular mechanisms and to reveal the role of miR-30d-5p in PCOS. The results of this study indicated that miR-30d-5p may be a new therapeutic target for the treatment of PCOS.

\section{Materials and methods}

Cell culture. Rat ovarian granulosa cells (cat. no. CC-R050) were purchased from Shanghai Mingjin Biotechnology Co., Ltd. Rat granulosa cells were then cultured in DMEM/Ham's nutrient mixture F-12 medium (Gibco; Thermo Fisher Scientific, Inc.) containing 10\% fetal bovine serum (Gibco; Thermo Fisher Scientific, Inc.) and $100 \mathrm{U} / \mathrm{ml}$ penicillin and $100 \mathrm{mg} / \mathrm{ml}$ streptomycin (Gibco; Thermo Fisher Scientific, Inc.) in a humidified atmosphere containing $5 \% \mathrm{CO}_{2}$ at $37^{\circ} \mathrm{C}$.

Cell transfection.miR-30d-5pmimic (cat.no.miR10000461-1-5) or the negative control (NC) of the miR-30d-5p mimic (NC scrambled miR-30d-5p mimic; cat. no. miR01201-1-5) were purchased from Guangzhou RiboBio Co., Ltd. Rat ovarian granulosa cells $\left(5 \times 10^{4}\right.$ cells per well) were cultured in six-well plates overnight at $37^{\circ} \mathrm{C}$ prior to transfection. Cells were then transfected with $1 \mu \mathrm{g}$ Smad2-plasmid (cat. no. sc-421525-ACT; Santa Cruz Biotechnology, Inc.), $1 \mu \mathrm{g}$ control plasmid (cat. no. sc-437275; Santa Cruz Biotechnology, Inc.), $100 \mathrm{nM}$ miR-30d-5p mimics, $100 \mathrm{nM} \mathrm{NC}$ miR-30d-5p mimics, $100 \mathrm{nM}$ miR-30d-5p mimics $+1 \mu \mathrm{g}$ control plasmid (Mimics + plasmid) or $100 \mathrm{nM}$ miR-30d-5p mimics + $1 \mu \mathrm{g}$ Smad2-plasmid (Mimics + Smad2 plasmid) using Lipofectamine ${ }^{\mathrm{TM}} 2000$ (Invitrogen; Thermo Fisher Scientific, Inc.) according to the manufacturer's protocol. Following 48 -h of incubation at $37^{\circ} \mathrm{C}$, the transfection efficiency was detected by reverse transcription-quantitative PCR (RT-qPCR).

$R N A$ isolation and $R T-q P C R$. Following transfection as previously described, total RNA from rat granulosa cells (24-well plates at a density of $2 \times 10^{5}$ cells per well) were extracted using TRIzol $^{\circledR}$ (Invitrogen; Thermo Fisher Scientific, Inc.) according to the manufacturer's protocol. Total RNA was quantified using a NanoDrop-1000 spectrophotometer (Thermo Fisher Scientific, Inc.). RNA was reverse transcribed into cDNA using PrimeScript RT reagent kit (Takara Bio, Inc.) according to the manufacturer's protocol. The following reverse transcription conditions were used: Initial denaturation at $37^{\circ} \mathrm{C}$ for $15 \mathrm{~min}$, followed by $85^{\circ} \mathrm{C}$ for $5 \mathrm{sec}$ and $4^{\circ} \mathrm{C}$ for $5 \mathrm{~min}$. The relative expression of miRNAs were determined using TaqMan miRNA assay (Thermo Fisher Scientific, Inc.) on an ABI 7500 Fast Instrument (Applied Biosystems; Thermo Fisher Scientific, Inc.). The following thermocycling conditions were used for this qPCR: Initial denaturation at $95^{\circ} \mathrm{C}$ for $15 \mathrm{~min}$, followed by 40 cycles at $95^{\circ} \mathrm{C}$ for $10 \mathrm{sec}$ and at $60^{\circ} \mathrm{C}$ for $60 \mathrm{sec}$. The relative levels of mRNA were quantified using the SYBR Premix Ex Taq (Takara Bio, Inc.) according to the manufacturer's protocol. The following thermocycling conditions were used for this qPCR: Initial denaturation at $95^{\circ} \mathrm{C}$ for $3 \mathrm{~min}$, followed by 40 cycles at $95^{\circ} \mathrm{C}$ for $5 \mathrm{sec}$ and at $60^{\circ} \mathrm{C}$ for $30 \mathrm{sec} . \beta$-actin and U6 were used for mRNA and miRNA normalization, respectively. The primers utilized were as follows: miR-30d-5p forward, 5'-CCTGTTGGTGCA CTTCCTAC-3' and reverse, 5'-TGCAGTAGTTCTCCAGCT GC-3'; Smad2 forward, 5'-GTTCCTGCCTTTGCTGAG AC-3' and reverse, 5'-TTCTCTTTGCCAGGAATGCT-3'; Smad3 forward, 5'-GGAGGAGAAATGGTGCGAGAA-3' and reverse, 5'-GCCACAGGCGGCAGTAGAT-3'; $\beta$-actin forward, 5'-CGAGCGTGGCTACAGCTTC-3' and reverse, 5'-GTCACGCACGATTTCCCTCT-3'; and U6 forward, 5'-ATGACGTCTGCCTTGGAGAAC-3' and reverse, 5'-TCA GTGTGCTACGGAGTTCAG-3'. Relative gene expression was quantified using the $2^{-\Delta \Delta \mathrm{Cq}}$ method (25). Experiments were repeated in triplicate.

Dual-luciferase reporter assay. TargetScan (http://www. targetscan.org/vert_71/) was used to predict the potential target genes of miR-30d-5p. The results identified binding sites between miR-30d-5p and Smad2. A luciferase reporter assay was subsequently performed to confirm the binding sites between miR-30d-5p and Smad2 3'UTR. The 3'UTR of Smad 2 containing the miR-30d-5p putative wild-type (WT) and mutant (MUT) binding site were cloned into the psiCHECK-2 luciferase reporter vector (Promega Corporation). Rat granulosa cells were plated $\left(5 \times 10^{4}\right.$ per well) in 24-well plates and co-transfected with miR-30d-5p mimic or NC and psiCHECK-2-Smad2-3'UTR-WT or psiCHECK-2Smad2-3'UTR-MUT using Lipofectamine ${ }^{\mathrm{TM}} 2000$ (Invitrogen; Thermo Fisher Scientific, Inc.). Following $48 \mathrm{~h}$ of incubation at $37^{\circ} \mathrm{C}$, the luciferase activity was measured using a dual-luciferase reporter assay system (Promega Corporation). Renilla luciferase activity was used as an internal control. Experiments were repeated in triplicate.

Western blot analysis. Following transfection as previously described, total protein samples were extracted from rat granulosa cells $\left(6-\right.$ well plates at a density of $4 \times 10^{5}$ cells per well) following transfection as previously described using RIPA lysis buffer (Gibco; Thermo Fisher Scientific, Inc.) containing phenylmethylsulfonyl fluoride (Beyotime Institute of Biotechnology) and phosphatase inhibitor cocktail (cat. no. ab201112; Abcam). Protein concentrations were determined using the bicinchoninic acid method. An equal quantity of protein $(40 \mu \mathrm{g})$ obtained from cell lysates were separated via $10 \%$ SDS-PAGE gel and then electrophoretically transferred 
A

Position $8719-8725$ of Smad2 3' UTR

hsa-miR-30d-5p

Mutant position of Smad2 $3^{\prime}$ UTR

B

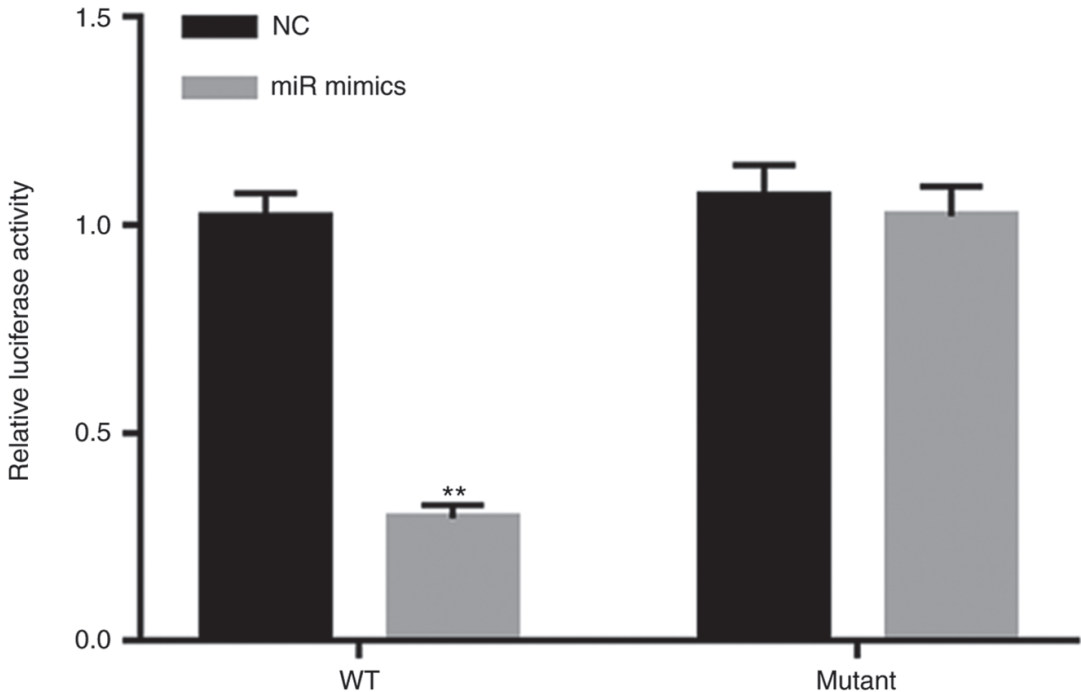

Figure 1. Targeting relationship between miR-30d-5p and Smad2. (A) TargetScan was used to predict binding sites between miR-30d-5p and Smad2. (B) Dual luciferase reporter gene assay was used to detect the targeting relationship between miR-30d-5p and Smad2. Data are presented as the mean \pm standard deviation. ${ }^{* *} \mathrm{P}<0.01$ vs. NC group. miR, microRNA; NC, negative control; UTR, untranslated region; WT, wild-type.

onto PVDF membranes (Immobilon; EMD Millipore). The membranes were blocked with 5\% non-fat dry milk for $1 \mathrm{~h}$ at room temperature, and incubated with the following primary antibodies overnight at $4^{\circ} \mathrm{C}$ : Phosphorylated (p)-Smad2 (cat. no. 18338; 1:1,000; Cell Signaling Technology, Inc.), Smad2 (cat. no. 8685; 1:1,000; Cell Signaling Technology, Inc.), p-Smad3 (cat. no. 9520; 1:1,000; Cell Signaling Technology, Inc.), Smad3 (cat. no. 9523; 1:1,000; Cell Signaling Technology, Inc.) and $\beta$-actin (cat. no. 4970; 1:1,000; Cell Signaling Technology, Inc.). Membranes were then further incubated with horseradish peroxidase-conjugated secondary antibodies (cat. no. 7074; 1:1,000; Cell Signaling Technology, Inc.) at room temperature for $1 \mathrm{~h}$. Proteins bands were visualized using an enhanced chemiluminescence kit (Pierce; Thermo Fisher Scientific, Inc.) and quantified using ImageJ software (version 1.8.0; National Institutes of Health). Experiments were repeated for three times.

MTT assay. Rat granulosa cells were seeded into 96-well plate at $1 \times 10^{4}$ cells per well and cultured for $24 \mathrm{~h}$ at $37^{\circ} \mathrm{C}$. Cells were then transfected as previously described for 12 , 24 or 48 h. Cells were incubated with $20 \mu \mathrm{l}$ MTT $(5 \mathrm{mg} / \mathrm{ml}$; Sigma-Aldrich; Merck $\mathrm{KGaA}$ ) for $4 \mathrm{~h}$ at $37^{\circ} \mathrm{C}$, after which the DMEM/Ham's nutrient mixture F-12 medium was replaced with $150 \mu \mathrm{l}$ DMSO to dissolve the purple formazan product. The optical density at a wavelength of $490 \mathrm{~nm}$ was recorded using a microplate reader (Multiskan FC; Thermo Fisher Scientific, Inc.). Experiments were repeated in triplicate.

Flow cytometry analysis. An Annexin V-FITC/propidium iodide (PI) apoptosis detection kit (Abcam) was used to evaluate cell apoptosis. Following 48 h of transfection, rat granulosa cells were collected and washed with cold PBS, after which cells were treated with $0.25 \%$ trypsin to digest the cells. Cell pellets were collected, centrifuged with $1,000 \mathrm{x} g$ for $5 \mathrm{~min}$ at $20^{\circ} \mathrm{C}$ and suspended in PBS. Subsequently, the supernatant was discarded and re-suspended with a binding buffer containing Annexin V-FITC and PI for $15 \mathrm{~min}$ in the dark at room temperature. Flow cytometry (FACSCalibur; BD Biosciences) was used to evaluate cell apoptotic rate and the data was analyzed using FlowJo software (version 7.6.1; FlowJo LLC). Experiments were repeated in triplicate.

Statistical analysis. Statistical analysis was performed using SPSS 13.0 statistical software (SPSS, Inc.). Data were presented as mean \pm standard deviation of three independent experiments. A Student's t-test was used to compare the differences between two groups. One-way ANOVA followed by Tukey's post hoc test was used to analyze the differences between more than two groups. $\mathrm{P}<0.05$ was considered to indicate a statistically significant difference.

\section{Results}

Smad2 is a target gene of miR-30d-5p. Bioinformatics analysis predicted that miR-30d-5p had hundreds of potential target genes including Smad2 (Fig. 1A). To confirm the relationship between miR-30d-5p and Smad2, dual-luciferase reporter assay was performed. As presented in Fig. 1B, the luciferase activity of the miR-30d-5p mimic group following transfection with the WT-Smad2 3'-UTR luciferase reporter vector was significantly decreased compared with the NC group, whilst 

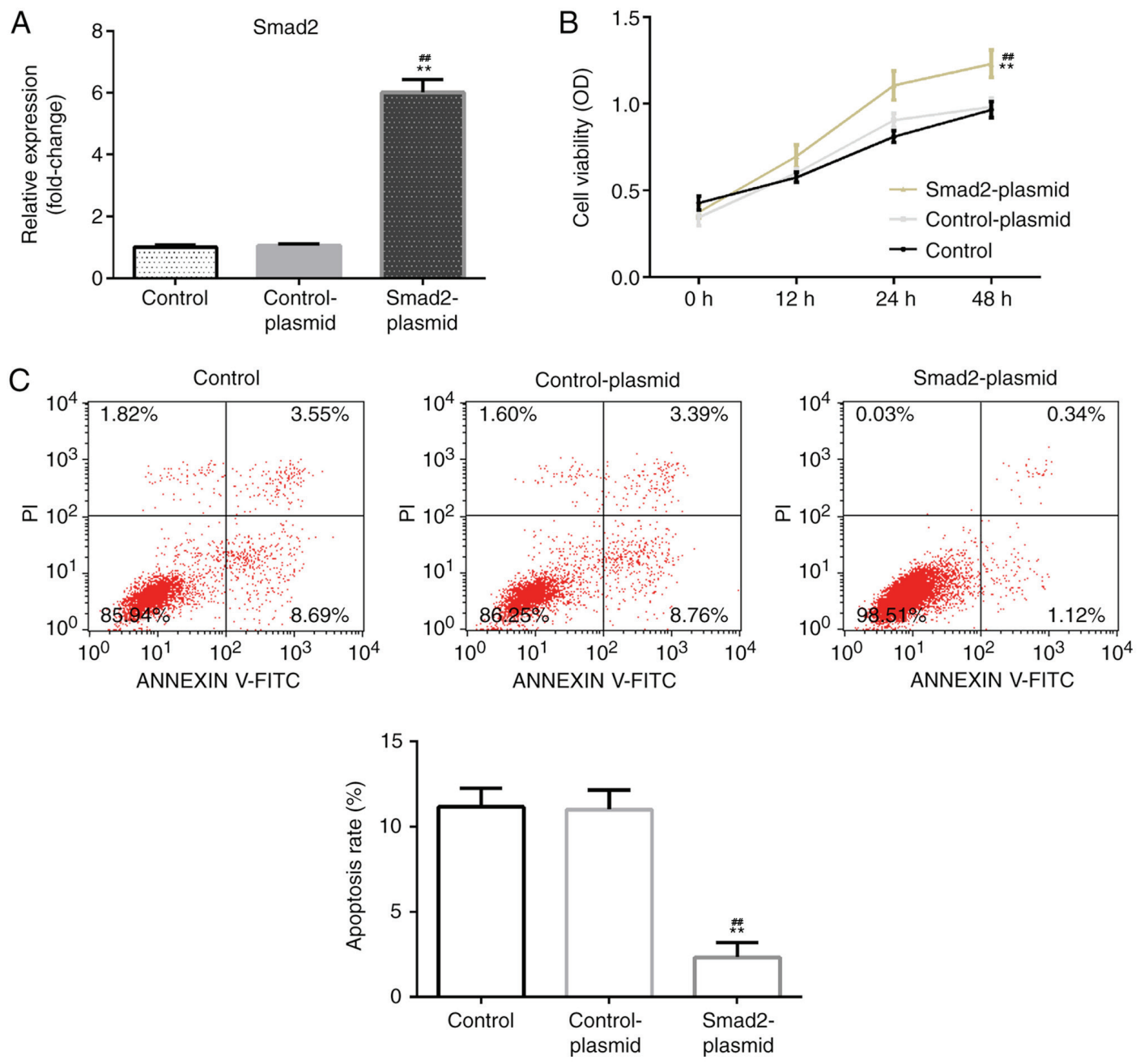

Figure 2. Effect of Smad2 overexpression on rat ovarian granulosa cells. (A) Rat ovarian granulosa cells were transfected with the Smad2 plasmid or control-plasmid for $48 \mathrm{~h}$. Subsequently, reverse transcription-quantitative PCR was performed to detect the mRNA level of Smad2 in rat ovarian granulosa cells. (B) an MTT assay was performed to detect cell proliferation and (C) flow cytometry was used to determine cell apoptosis. Data are presented as the mean \pm standard deviation. ${ }^{* *} \mathrm{P}<0.01$ vs. control group, ${ }^{\# \#} \mathrm{P}<0.05$ vs. control-plasmid group. PI, propidium iodide; miR, microRNA; NC, negative control.
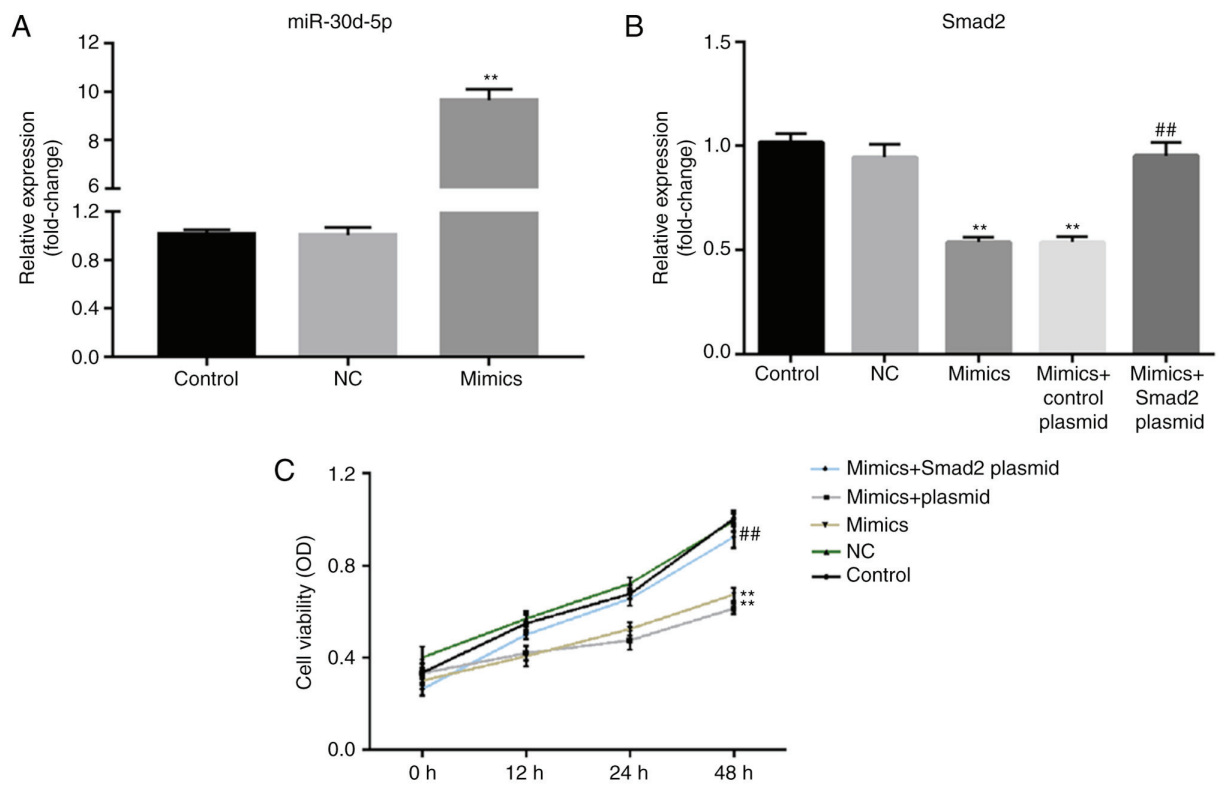

Figure 3. Effect of miR-30d-5p overexpression on proliferation of rat granulosa cells. Rat granulosa cells were transfected with miR-30d-5p mimic, NC, miR-30d-5p mimic + control plasmid or miR-30d-5p mimic + Smad2 plasmid. Reverse transcription-quantitative PCR was then performed to detect the expression of (A) miR-30d-5p and (B) Smad2. (C) An MTT assay was performed to detect the proliferation of rat granulosa cells. Data are presented as the mean \pm standard deviation. ${ }^{* *} \mathrm{P}<0.01$ vs. $\mathrm{NC}$ group; ${ }^{\# \#} \mathrm{P}<0.01$ vs. miR-30d-5p mimics group. miR, microRNA; NC, negative control; OD, optical density. 

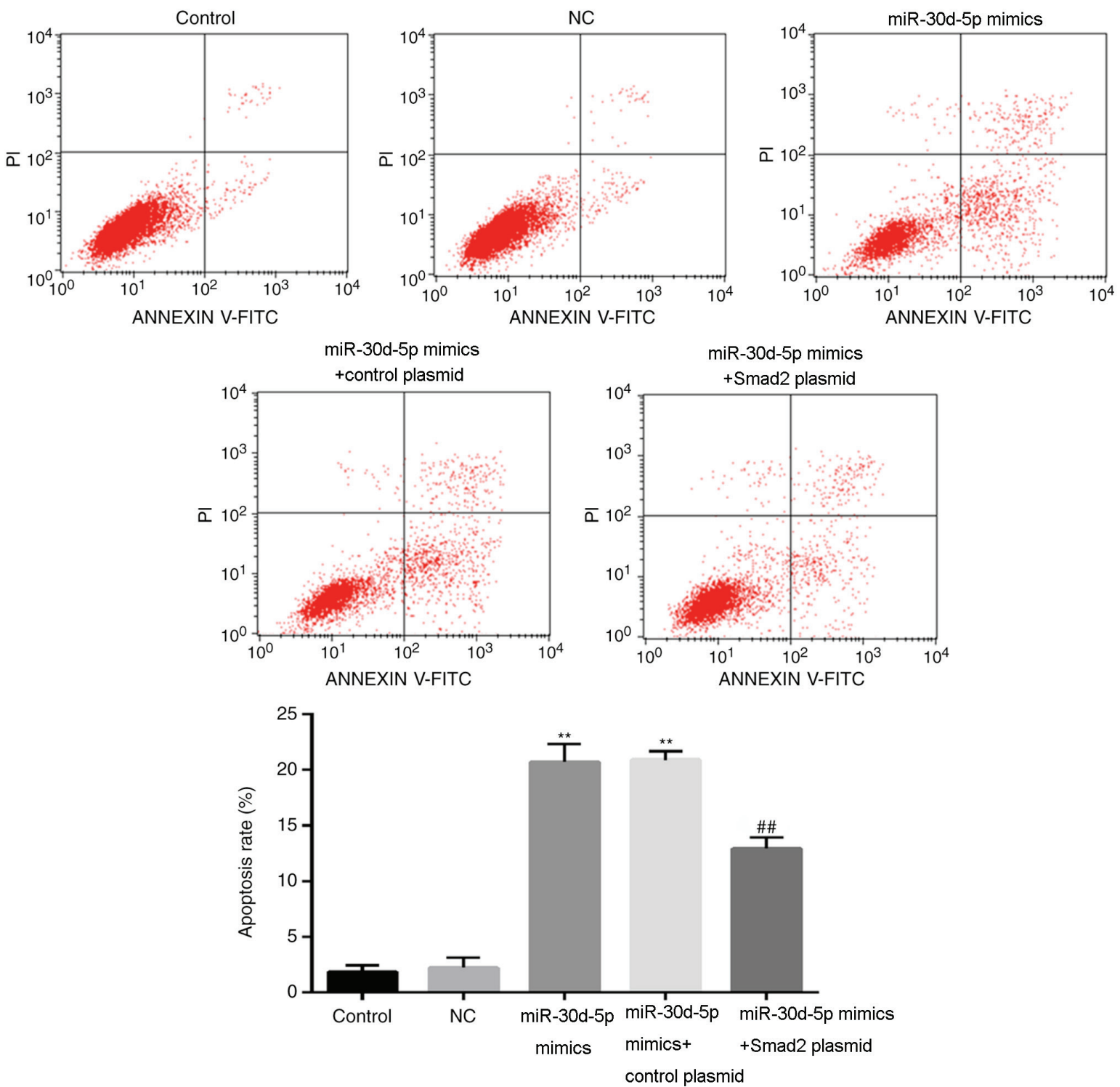

Figure 4. Effect of miR-30d-5p overexpression on apoptosis of rat granulosa cells. Rat granulosa cells were transfected with miR-30d-5p mimic, NC, miR-30d-5p mimic + control plasmid or miR-30d-5p mimic + Smad2 plasmid. Flow cytometry was subsequently performed to detect the apoptosis of rat granulosa cells. are presented as the mean \pm standard deviation. ${ }^{* *} \mathrm{P}<0.01$ vs. $\mathrm{NC}$ group; ${ }^{\# \#} \mathrm{P}<0.01$ vs. miR-30d-5p mimics group. miR, microRNA; NC, negative control; PI, propidium iodide.

there was no significant difference in miR-30d-5p mimics group transfected with MUT-Smad2 3'-UTR luciferase reporter vector compared with the NC group. The results indicated that Smad2 was the target gene of miR-30d-5p.

Smad2 overexpression reduces apoptosis and increases the viability of rat ovarian granulosa cells. The effect of Smad2 overexpression on rat ovarian granulosa cell viability and apoptosis was investigated. Rat ovarian granulosa cells were transfected with Smad2 plasmid or control-plasmid for $48 \mathrm{~h}$. RT-qPCR was then performed to detect transfection efficiency. It was determined that, compared with the control group, the Smad2 plasmid significantly enhanced Smad2 mRNA levels in rat ovarian granulosa cells (Fig. 2A). Further analysis indicated that when compared with the control and control plasmid group, the Smad2 plasmid significantly enhanced rat ovarian granulosa cell viability (Fig. 2B) and reduced cell apoptosis (Fig. 2C).
miR-30d-5p decreases the viability of rat ovarian granulosa cells by targeting Smad2. To further confirm whether Smad2 was involved with miR-30d-5p in ovarian granulosa cells, rat ovarian granulosa cells were transfected with miR-30d-5p mimics, NCs, miR-30d-5p mimics + control plasmid or miR-30d-5p mimics + Smad2-plasmid for $48 \mathrm{~h}$. After transfection with miR-30d-5p mimics for $48 \mathrm{~h}$, transfection efficiency was detected via RT-qPCR, where the level of miR-30d-5p significantly increased compared with the NC group (Fig. 3A). In addition, it was determined that miR-30d-5p mimics significantly reduced the level of Smad2 mRNA in rat ovarian granulosa cells compared with the NC group. This decrease was also significantly reversed following Smad2-plasmid co-transfection (Fig. 3B). The viability of ovarian granulosa cells was examined to confirm the biological role of miR-30d-5p in ovarian granulosa cells. An MTT assay demonstrated that following transfection with miR-30d-5p mimics, rat ovarian granulosa cell viability was markedly decreased compared 
A

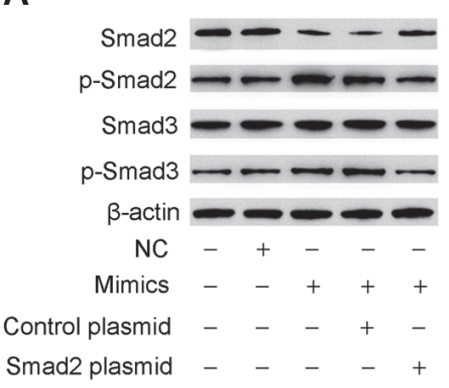

B

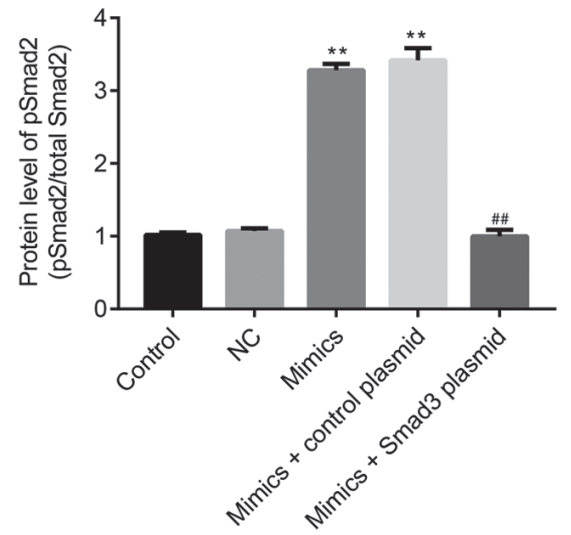

E

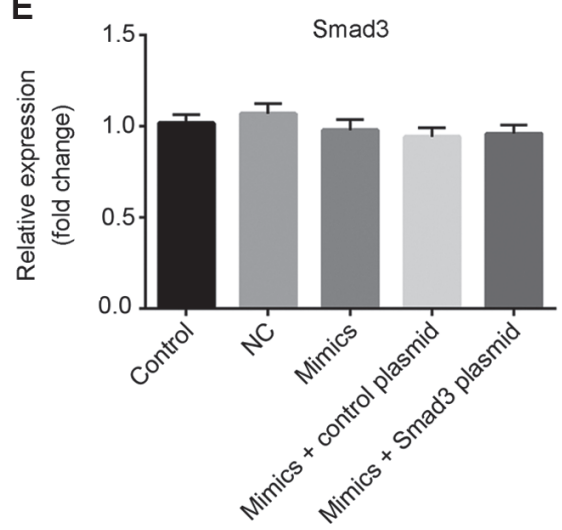

C

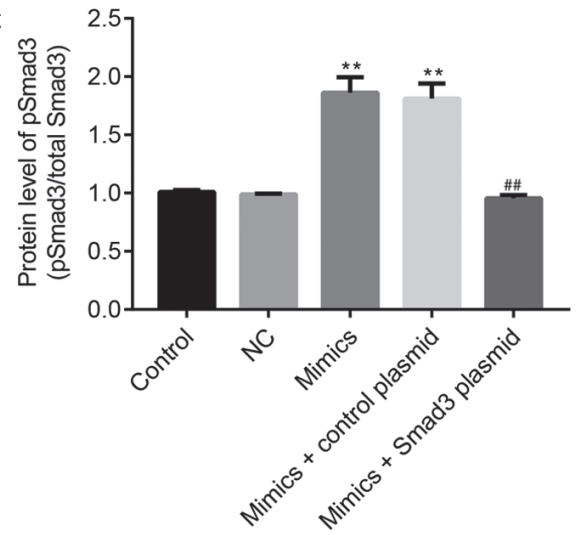

D

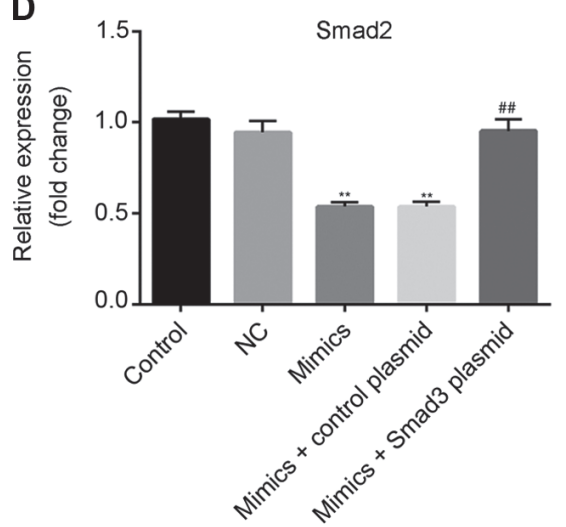

Figure 5. Effect of miR-30d-5p overexpression on p-Smad2/Smad2, p-Smad3/Smad3 expression rat granulosa cells. Rat granulosa cells were transfected with miR-30d-5p mimic, NC, miR-30d-5p mimic + control plasmid or miR-30d-5p mimic + Smad2 plasmids. (A) Western blotting was performed to detect the protein levels of p-Smad2/Smad 2 and p-Smad3/Smad3 in rat granulosa cells. (B and C) p-Smad2/Smad2 and p-Smad3/Smad3 ratio was calculated. Reverse transcription-quantitative PCR was then performed to detect the mRNA levels of (D) Smad2 and (E) Smad3 in rat granulosa cells. Data are presented as the mean \pm standard deviation. ${ }^{* *} \mathrm{P}<0.01$ vs. $\mathrm{NC}$ group; ${ }^{\# \#} \mathrm{P}<0.01$ vs. miR-30d-5p mimics group. miR, microRNA; , phosphorylated; NC, negative control.

with the NC group. This decrease was reversed following transfection with the Smad2-plasmid (Fig. 3C). The results indicated that overexpression of Smad2 reversed the effects of miR-30d-5p on ovarian granulosa cell proliferation.

miR-30d-5p promotes the apoptosis of rat ovarian granulosa cells by targeting Smad2. Flow cytometry results demonstrated that the apoptotic rate of the miR-30d-5p mimics group was significantly increased compared with the control group (Fig. 4). The apoptotic rate of the miR-30d-5p mimic + Smad2 plasmid group was significantly lower compared with the miR-30d-5p mimics transfection group (Fig. 4). These results indicated that overexpression of Smad 2 reversed the effects of miR-30d-5p on ovarian granulosa cell apoptosis.

miR-30d-5p increases the ratio of $p$-Smad2/Smad2 and p-Smad 3/Smad 3 in rat ovarian granulosa cells. Proliferation can be regulated by the Smad protein pathway (26). As presented in Fig. 5, after transfection with miR-30d-5p mimics, the protein (Fig. 5A and B) and mRNA (Fig. 5D) expression of Smad2 was significantly decreased, whilst the protein (Fig. 5A) and mRNA (Fig. 5E) expression of Smad3 exhibited no significant changes. In addition, the protein expression of the phosphorylated (active) forms of Smad2 and Smad3 (Fig. 5A-C) were markedly increased in rat ovarian granulosa cells following miR-30d-5p mimic transfection. Notably, overexpression of Smad2 reversed the effects of miR-30d-5p on the expression of $\mathrm{p}-\mathrm{Smad} 2 / \mathrm{Smad} 2$ and $\mathrm{p}-\mathrm{Smad} 3 / \mathrm{Smad} 3$ in ovarian granulosa cells.

\section{Discussion}

PCOS is the most common metabolic and endocrine disease in women of childbearing age, involving multiple factors and a complicated etiology and pathophysiology (1). Researchers have identified that PCOS is associated with disorders of multiple factors regulating the ovaries. miR-30d-5p has been reported to serve important roles in the regulation of cell proliferation, invasion and apoptosis in a variety of tumor cells $(27,28)$. A previous study also reported that miR-30d-5p levels increased during cultured granulosa cell secretion of FSH-mediated progesterone (21), indicating that it may be closely associated with PCOS. In the present study, the results implied that miR-30d-5p might regulate the proliferation and apoptosis of ovarian granulosa cells by targeting Smad2, thus serving an important role in PCOS.

Previous reports have indicated that miRNAs may be involved in the pathogenesis of PCOS $(29,30)$. miR-324-3p levels have also been demonstrated to decrease in the ovaries of PCOS rats (31). Overexpression of miR-324-3p reduces the proliferation and induces the apoptosis of granulosa cells by targeting Wnt family member 2B (31). In addition, it has been revealed that miR-141-3p is markedly decreased in the ovaries of rat PCOS models and that apoptosis is inhibited in 
rat ovarian granulosa cells by targeting death associated protein kinase 1 (32). A previous study demonstrated that miR-30d-5p is markedly downregulated during cultured granulosa cell secretion of FSH-mediated progesterone (21). As a member of Smad protein family, Smad2 serves a key role in regulating cell proliferation and apoptosis. Abnormal proliferation and/or apoptosis in granulosa cells serves an important role in PCOS $(8,9)$. However, the relationship between miR-30d-5p and Smad2 remains unclear. In the present study, a dual-luciferase reporter assay confirmed that Smad2 was a target gene of miR-30d-5p and that Smad2 overexpression enhanced rat ovarian granulosa cell proliferation and inhibited cell apoptosis. To understand the role of miR-30d-5p in ovarian granulosa cells, samples were transfected with miR-30d-5p mimics. The results demonstrated that miR-30d-5p inhibited cell growth and promoted apoptosis, indicating that miR-30d-5p could be involved in the regulation of rat ovarian granulosa cell growth. Furthermore, Smad2 plasmid co-transfection reversed all the inhibitory effects of miR-30d-5p on rat ovarian granulosa cell viability and apoptosis.

Previous studies have reported that the endometrium of women with PCOS exhibits decreases in the inhibitory activity of the cell cycle from the G1 to S phase via the action of the Smad protein, thereby inducing cell cycle progression $(33,34)$. Smad proteins constitute regulatory molecules of cellular proliferation and apoptosis (35). To better understand the mechanisms of miR-30d-5p used in the regulation of ovarian granulosa cell survival, the participation of the Smad pathway was evaluated in the present study. The results demonstrated that the levels of Smad 2 significantly decreased, whilst the p-Smad2 and $\mathrm{p}-\mathrm{Smad} 3$ protein levels in the miR-30d-5p mimic group markedly increased when compared with the control group. Additionally, these effects could be reversed by Smad2 overexpression. The deregulation of Smad2 proteins may be associated with the miR-30d-5p-induced apoptosis of ovarian granulosa cells. However, further studies are required to understand the role of miR-30d-5p and Smad2 in the pathogenesis of PCOS.

In conclusion, the present results indicated that $\operatorname{Smad} 2$ was a direct target of miR-30d-5p. miR-30d-5p was also determined to promote ovarian granulosa cells apoptosis by targeting Smad2. The results of this study indicated that miR-30d-5p may be a new therapeutic target for PCOS treatment.

\section{Acknowledgements}

Not applicable.

\section{Funding}

No funding was received.

\section{Availability of data and materials}

The datasets used and/or analyzed during the current study are available from the corresponding author on reasonable request.

\section{Authors' contributions}

MY wrote the manuscript and analyzed and interpreted the data. JL designed the study and revised the manuscript. All authors read and approved the final manuscript.

\section{Ethics approval and consent to participate}

Not applicable.

\section{Patient consent for publication}

Not applicable.

\section{Competing interests}

The authors declare that they have no competing interests.

\section{References}

1. Norman RJ, Dewailly D, Legro RS and Hickey TE: Polycystic ovary syndrome. Lancet 370: 685-697, 2007.

2. Fux Otta C, Fiol de Cuneo M and Szafryk de Mereshian P: Polycystic ovary syndrome: Physiopathology review. Rev Fac Cien Med Univ Nac Cordoba 70: 27-30, 2013 (In Spanish).

3. McGee EA and Hsueh AJ: Initial and cyclic recruitment of ovarian follicles. Endocr Rev 21: 200-214, 2000.

4. Craig J, Orisaka M, Wang H, Orisaka S, Thompson W, Zhu C, Kotsuji $\mathrm{F}$ and Tsang BK: Gonadotropin and intra-ovarian signals regulating follicle development and atresia: The delicate balance between life and death. Front Biosci 12: 3628-3639, 2007.

5. Hsueh AJ, Kawamura K, Cheng Y and Fauser BC: Intraovarian control of early folliculogenesis. Endocr Rev 36: 1-24, 2015.

6. de Melo AS, Dias SV, Cavalli Rde C, Cardoso VC, Bettiol H, Barbieri MA, Ferriani RA and Vieira CS: Pathogenesis of polycystic ovary syndrome: Multifactorial assessment from the foetal stage to menopause. Reproduction 150: R11-R24, 2015.

7. Qiao J and Feng HL: Extra- and intra-ovarian factors in polycystic ovary syndrome: Impact on oocyte maturation and embryo developmental competence. Hum Reprod Update 17: 17-33, 2011.

8. Onalan G, Selam B, Baran Y, Cincik M, Onalan R, Gündüz U, Ural AU and Pabuccu R: Serum and follicular fluid levels of soluble Fas, soluble Fas ligand and apoptosis of luteinized granulosa cells in PCOS patients undergoing IVF. Hum Reprod 20: 2391-2395, 2005.

9. Shalev E, Goldman S and Ben-Shlomo I: The balance between MMP-9 and MMP-2 and their tissue inhibitor (TIMP)-1 in luteinized granulosa cells: Comparison between women with PCOS and normal ovulatory women. Mol Hum Reprod 7: 325-331, 2001

10. Krol J, Loedige I and Filipowicz W: The widespread regulation of microRNA biogenesis, function and decay. Nat Rev Genet 11: 597-610, 2010.

11. Wang Y and Lee CG: MicroRNA and cancer-focus on apoptosis. J Cell Mol Med 13: 12-23, 2009.

12. Bueno MJ, Pérez de Castro I and Malumbres M: Control of cell proliferation pathways by microRNAs. Cell Cycle 7: 3143-3148, 2008.

13. Carletti MZ, Fiedler SD and Christenson LK: MicroRNA 21 blocks apoptosis in mouse periovulatory granulosa cells. Biol Reprod 83: 286-295, 2010.

14. YaoG, Yin M,Lian J,Tian H,LiuL,LiX and Sun F: MicroRNA-224 is involved in transforming growth factor-beta-mediated mouse granulosa cell proliferation and granulosa cell function by targeting Smad4. Mol Endocrinol 24: 540-551, 2010.

15. Zheng M, Hou L, Ma Y, Zhou L, Wang F, Cheng B, Wang W, Lu B, Liu P, Lu W and Lu Y: Exosomal let-7d-3p and miR-30d-5p as diagnostic biomarkers for non-invasive screening of cervical cancer and its precursors. Mol Cancer 18: 76, 2019.

16. Hosseini SM, Soltani BM, Tavallaei M, Mowla SJ, Tafsiri E, Bagheri A and Khorshid HRK: Clinically significant dysregulation of hsa-miR-30d-5p and hsa-let-7b expression in patients with surgically resected non-small cell lung cancer. Avicenna J Med Biotechnol 10: 98-104, 2018.

17. Song Y, Song C and Yang S: Tumor-suppressive function of miR-30d-5p in prostate cancer cell proliferation and migration by targeting NT5E. Cancer Biother Radiopharm 33: 203-211, 2018.

18. He Y, Chen X, Yu Y, Li J, Hu Q, Xue C, Chen J, Shen S, Luo Y, Ren F, et al: LDHA is a direct target of miR-30d-5p and contributes to aggressive progression of gallbladder carcinoma. Mol Carcinog 57: 772-783, 2018 
19. Yu X,Zhao J and He Y: Long non-coding RNA PVT1 functions as an oncogene in human colon cancer through miR-30d-5p/RUNX2 axis. J BUON 23: 48-54, 2018

20. Jiang M, Wang H, Jin M, Yang X, Ji H, Jiang Y, Zhang H, Wu F, Wu G, Lai X, et al: Exosomes from MiR-30d-5p-ADSCs reverse acute ischemic stroke-induced, autophagy-mediated brain injury by promoting M2 microglial/macrophage polarization. Cell Physiol Biochem 47: 864-878, 2018.

21. Yao N, Yang BQ, Liu Y, Tan XY, Lu CL, Yuan XH and Ma X: Follicle-stimulating hormone regulation of microRNA expression on progesterone production in cultured rat granulosa cells. Endocrine 38: 158-166, 2010.

22. Massagué J: G1 cell-cycle control and cancer. Nature 432: 298-306, 2004.

23. Mishra L, Derynck R and Mishra B: Transforming growth factor-beta signaling in stem cells and cancer. Science 310: 68-71, 2005.

24. Syed V: TGF- $\beta$ signaling in cancer. J Cell Biochem 117: 1279-1287, 2016.

25. Livak KJ and Schmittgen TD: Analysis of relative gene expression data using real-time quantitative PCR and the 2(-Delta Delta C(T)) method. Methods 25: 402-408, 2001.

26. Meran S, Luo DD, Simpson R, Martin J, Wells A, Steadman R and Phillips AO: Hyaluronan facilitates transforming growth factor- $\beta 1$-dependent proliferation via CD44 and epidermal growth factor receptor interaction. J Biol Chem 286: 17618-17630, 2011.

27. Ye C, Yu X, Liu X, Dai M and Zhang B: miR-30d inhibits cell biological progression of Ewing's sarcoma by suppressing the MEK/ERK and PI3K/Akt pathways in vitro. Oncol Lett 15: 4390-4396, 2018.

28. Yao J, Liang L, Huang S, Ding J, Tan N, Zhao Y, Yan M, Ge C, Zhang Z, Chen T, et al: MicroRNA-30d promotes tumor invasion and metastasis by targeting Galphai 2 in hepatocellular carcinoma. Hepatology 51: 846-856, 2010.
29. Hossain MM, Cao M, Wang Q, Kim JY, Schellander K, Tesfaye D and Tsang BK: Altered expression of miRNAs in a dihydrotestosterone-induced rat PCOS model. J Ovarian Res 6: 36, 2013.

30. Roth LW, McCallie B, Alvero R, Schoolcraft WB, Minjarez D and Katz-Jaffe MG: Altered microRNA and gene expression in the follicular fluid of women with polycystic ovary syndrome. J Assist Reprod Genet 31: 355-362, 2014.

31. Jiang YC and Ma JX: The role of MiR-324-3p in polycystic ovary syndrome (PCOS) via targeting WNT2B. Eur Rev Med Pharmacol Sci 22: 3286-3293, 2018.

32. Li D, Xu D, Xu Y, Chen L, Li C, Dai X, Zhang L and Zheng L: MicroRNA-141-3p targets DAPK1 and inhibits apoptosis in rat ovarian granulosa cells. Cell Biochem Funct 35: 197-201, 2017.

33. Chen C, Sun MZ, Liu S, Yeh D, Yu L, Song Y, Gong L, Hao L, $\mathrm{Hu} J$ and Shao S: Smad4 mediates malignant behaviors of human ovarian carcinoma cell through the effect on expressions of E-cadherin, plasminogen activator inhibitor-1 and VEGF. BMB Rep 43: 554-560, 2010.

34. Goto N, Hiyoshi H, Ito I, Tsuchiya M, Nakajima Y and Yanagisawa J: Estrogen and antiestrogens alter breast cancer invasiveness by modulating the transforming growth factor- $\beta$ signaling pathway. Cancer Sci 102: 1501-1508, 2011.

35. Bacallao K, Plaza-Parrochia F, Cerda A, Gabler F, Romero C, Vantman D and Vega M: Levels of regulatory proteins associated with cell proliferation in endometria from untreated patients having polycystic ovarian syndrome with and without endometrial hyperplasia. Reprod Sci 23: 211-218, 2016.

(i) $($ ) This work is licensed under a Creative Commons Attribution-NonCommercial-NoDerivatives 4.0 International (CC BY-NC-ND 4.0) License. 